\title{
Cardiac Effects of Glucagon-Like Peptide 1 with Chitosan-Based Scaffold after Inducing Myocardial Infarction in Dogs
}

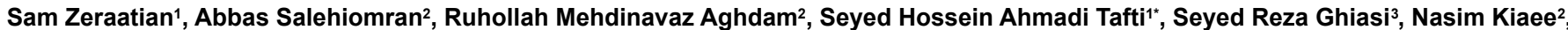
Shahram Rabbani ${ }^{2}$, Ali Ghiasedin ${ }^{4}$, Hanif Tabesh ${ }^{5}$, Nazafarin Kamalzade ${ }^{6}$

${ }^{1}$ Department of Cardiovascular Surgery, Tehran Heart Center (THC), Tehran University of Medical Sciences (TUMS), Tehran, Iran

${ }^{2}$ Department of Clinical Research, Tehran Heart Center (THC), Tehran University of Medical Sciences (TUMS), Tehran, Iran

${ }^{3}$ Department of Small Animal Internal Medicine, School of Veterinary Sciences, Islamic Azad University, Garmsar, Iran

${ }^{4}$ Biotechnology and Biomedical Group, School of Chemical Engineering, Tarbiat Modares University, Tehran, Iran

${ }^{5}$ School of Medicine, Shahid Beheshti University of Medical Sciences (SBMU), Tehran, Iran

${ }^{6}$ Department of Anesthesiology, Tehran University of Medical Sciences (TUMS), Tehran, Iran

\begin{abstract}
Aims: Glucagon-like peptide 1 (GLP-1) is one of the new choices in the management of diabetes mellitus because of its glucose regulatory effects. GLP-1 receptors are expressed not only in islet cells, kidney, lung, brain, and gastrointestinal tract, but also in the heart. The cardiac effects of GLP-1 play a major role in the choice to use this treatment, considering the expression of GLP-1 receptors in heart. Degradation by dipeptidyl peptidase-IV (DPPIV) makes GLP-1's half-life very short. In this study, the cardiac effects of GLP-1 with chitosan-based scaffold as well as the tissue changes after induction of myocardial infarction in canines were evaluated.

Method: Twelve canines of a similar breed and weight were included in this study. They were categorized into three groups: A case group treated with GLP-1 based on a chitosan scaffold, a group given chitosan with normal saline, and a control group given normal saline alone. Every four weeks after induction of infarction, the troponin-I serum level, regional wall motion abnormality (RWMA), angiogenesis, and microscopic and macroscopic tissue changes were analyzed.

Results: Angiogenesis and infarcted area thickness (which is inversely related to the subsequent risk of pseudoaneurysm development) were significantly higher in the case group compared with the other two groups ( $p$ value $<0.05$ ). Our case group recorded lower scores of RWMA compared with other canines ( $p$ value $=0.02$ ).

Conclusion: This investigation revealed that the new compound (GLP-1+chitosan) not only lengthens the releasing duration of GLP-1 but also has cardioprotective effects after myocardial infarction.
\end{abstract}

Keywords: Heart; Myocardial infarction; Glucagon-like peptide 1; Dogs; Diabetes mellitus

\section{Introduction}

Glucagon-like peptide 1 (GLP-1) is a gut-derived incretin hormone secreted in response to nutrients [1]. GLP-1 is used in the therapeutic management of diabetes because of its gluco-regulatory effects, including augmentation of glucose-stimulated insulin secretion, suppression of postprandial glucagon secretion, delayed gastric emptying, and hypothalamus-mediated satiety of appetite. GLP-1 receptors are expressed not only in islet cells, kidney, lung, brain, and gastrointestinal tract, but also in the heart $[2,3]$. Several studies have analyzed the effect of GLP-1 on myocardial infarction (MI) and reperfusion injury [4]. While the cardioprotective effects of glucoseinsulin-potassium infusion in patients with $\mathrm{MI}$ are controversial, later investigations have focused on GLP-1. It has been shown that GLP1 can be cardioprotective in a wide spectrum of animal models of myocardial ischemia and reperfusion injury [5].

Degradation by dipeptidyl peptidase-IV (DPPIV) makes GLP-1's half-life very short. Therefore, the use of a DPPIV inhibitor is necessary to prolong its half-life [6]. Longer half-life can also be achieved by putting GLP-1 on a chitosan scaffold, which is a new hypothesis proposed in this article. Bioavailability of the chitosan scaffold has been evaluated in both animals and human models for tissue engineering $[7,8]$.

In this study, we evaluated the effects of GLP-1 on cardiac function and microscopic tissue changes after MI in a canine model. A chitosan scaffold was used to increase the half-life of GLP-1 and the duration of its release.

\section{Materials and Methods}

Twelve mixed-breed dogs (11 males and one female) with weights of 20-25 kilograms and no history of cardiac problems were used for this study. They were sorted into three groups: A case group treated with GLP-1 on a chitosan scaffold (Figure 1), a group treated with chitosan and normal saline, and a control group treated with normal saline alone.

Baseline electrocardiograms were obtained in six leads (using four limbs). Induction of general anesthesia was done, by ketamine (11 mg/ $\mathrm{kg}, \mathrm{IM})$ and xylazine (1.1 $\mathrm{mg} / \mathrm{kg} \mathrm{IM})$ and maintained by inhalation

*Corresponding author: Seyed Hossein Ahmadi Tafti, M.D, Department of Cardiovascular Surgery, Tehran Heart Center (THC), Tehran University of Medical Sciences (TUMS), Tehran, Iran, Tel: 00989121153540; E-mail: hosseinahmaditafti@yahoo.com

Received July 26, 2015; Accepted October 07, 2015; Published October 15, 2015

Citation: Zeraatian S, Salehiomran A, Aghdam RM, Tafti SHA, Ghiasi SR (2015) Cardiac Effects of Glucagon-Like Peptide 1 with Chitosan-Based Scaffold after Inducing Myocardial Infarction in Dogs. Cardiol Pharmacol 4: 159. doi:10.4172/2329-6607.1000159

Copyright: @ 2015 Zeraatian S, et al. This is an open-access article distributed under the terms of the Creative Commons Attribution License, which permits unrestricted use, distribution, and reproduction in any medium, provided the original author and source are credited. 
Citation: Zeraatian S, Salehiomran A, Aghdam RM, Tafti SHA, Ghiasi SR (2015) Cardiac Effects of Glucagon-Like Peptide 1 with Chitosan-Based Scaffold after Inducing Myocardial Infarction in Dogs. Cardiol Pharmacol 4: 159. doi:10.4172/2329-6607.1000159

of halothan. Orotracheal intubation was performed and the animals underwent left craniolateral thoracotomy. The left anterior descending (LAD) coronary artery was ligated distal to first septal and diagonal branch origins (Figure 2). Dogs in each of the three groups received their specific treatment after the infarction was induced. We injected normal saline (in control group), chitosan, and chitosan plus GLP1 , directly into infarcted area of left myocardium (Figure 1).The thoracotomy incisions were closed using the Air and Water Tight procedure. Chitosan as a solution is combined with $1 \%$ Acetic acid and the $\mathrm{pH}$ increased to 6.5. After combination with GLP-1 and increasing its $\mathrm{pH}$ to 7.5 , it will be ready as hydrogel for final use.

Every four weeks after the induction of infarction, troponin-I serum levels and regional wall motion abnormality (RWMA), which is demonstrated by echocardiography, were compared among the three groups. One dog from each group was also euthanized at four-week intervals. A Solution, consist of Sodium pentobarbital , $390 \mathrm{mg}$ plus sodium phenytoin, $50 \mathrm{mg} / \mathrm{ml}$ by the dose of $0.22 \mathrm{ml} / \mathrm{kg}$ as IV injection ( $\sim 86 \mathrm{mg} / \mathrm{kg}$ pentobarbital) used for all euthanasia. Before this step, ketamine $(30 \mathrm{mg} / \mathrm{kg}, \mathrm{IM})$ used to induce anaesthesia then heart was harvested and the thicknesses of normal and infarcted cardiac tissue were grossly measured. Sizes of the infarcted areas were also compared quantitatively using JImage software version 2 (Figure 3). After tissues were fixed in $10 \%$ buffered formalin, pathologic studies of the angiogenesis after infarction were evaluated by hematoxylin and eosin (H and $\mathrm{E}$ ) and anti-CD34 staining (Figure 4-6). One of the canines in the case group died on week 14 and was excluded from this study. The pathologist was blinded to the control and experimental groups.

All procedures were performed in accordance with the "Guide for the Care and Use of Laboratory Animals" arranged by the Institute of Laboratory Animal Resources and with prior approval by the Animal Experimentation Committee of the Faculty of Medicine, Tehran University of Medical Sciences (TUMS).

All data analyses were blinded. Data were presented with mean and standard deviation (SD), and cardiac variables were compared among treatment groups using the Kruskal-Wallis test. Statistical analyses were performed via SPSS version 19 (SPSS Inc., Chicago, Illinois).

\section{Results}

There were three dogs in the GLP-1+chitosan case group, four in the chitosan group, and four in the control group. Three of this study's

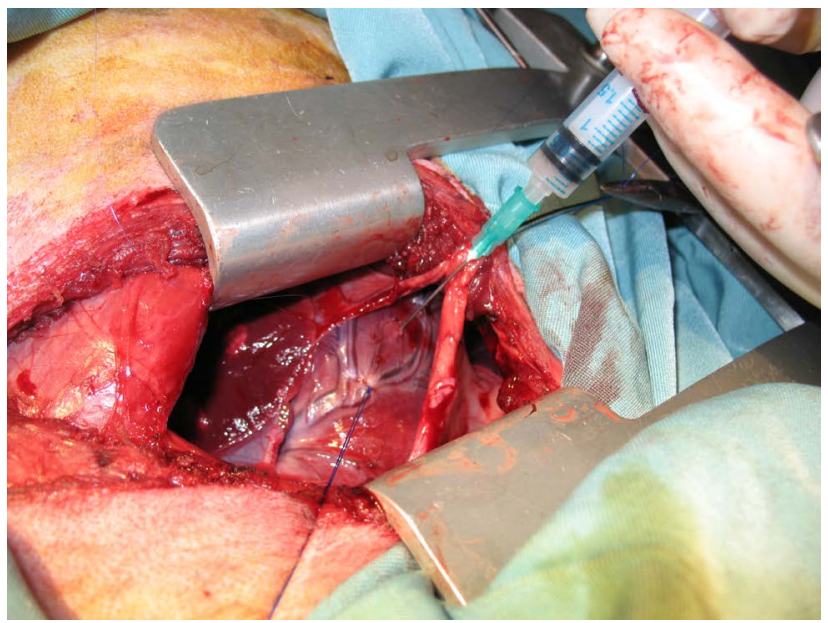

Figure1: Injection of GLP-1 with chitosan based scaffold into the infarcted zone.

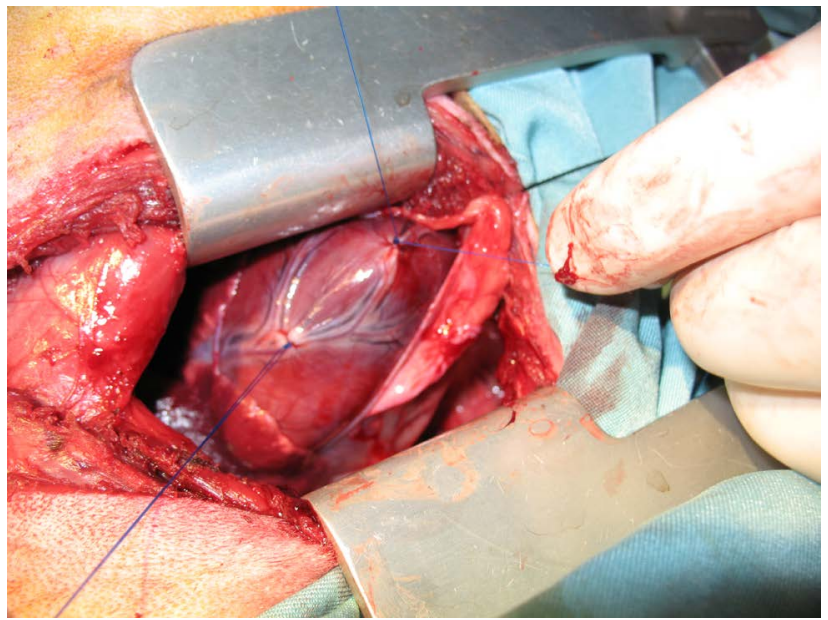

Figure2: Ligation of left anterior descending (LAD) artery for inducing myocardial infarction (MI).

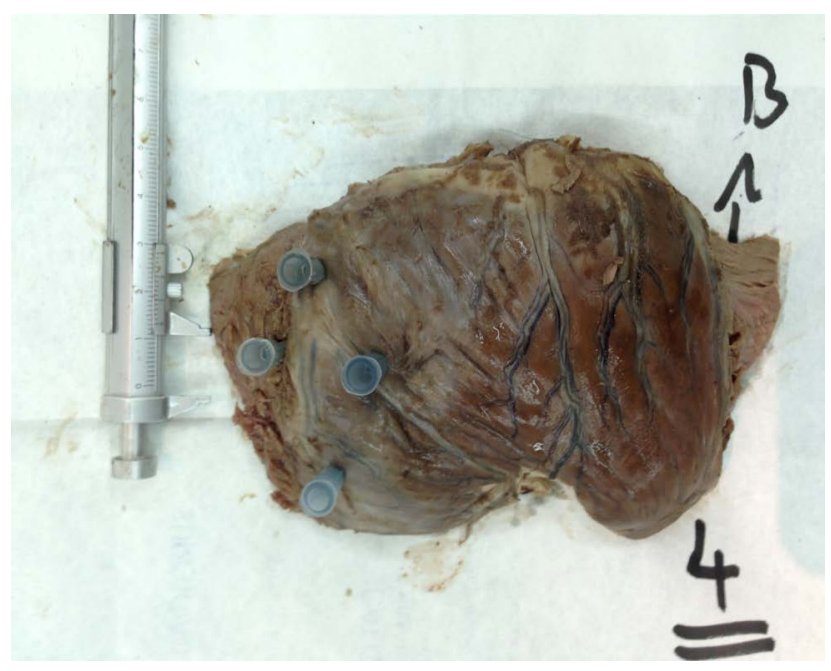

Figure 3: Preparation of infarcted cardiac tissue for Image $\mathrm{J}$ software

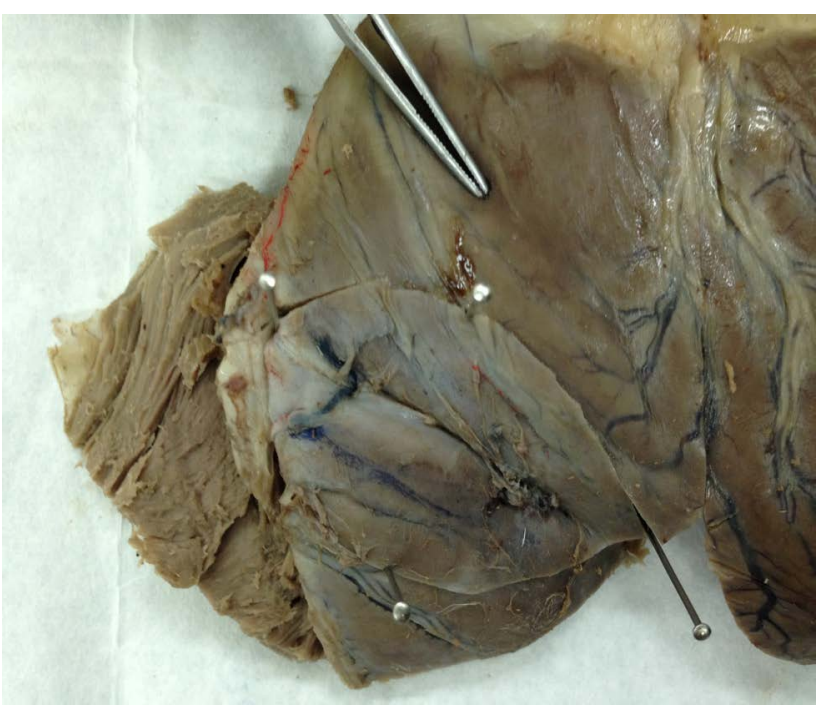

Figure 4: Cardiac tissue fixed in 10\% buffered formalin 
Citation: Zeraatian S, Salehiomran A, Aghdam RM, Tafti SHA, Ghiasi SR (2015) Cardiac Effects of Glucagon-Like Peptide 1 with Chitosan-Based Scaffold after Inducing Myocardial Infarction in Dogs. Cardiol Pharmacol 4: 159. doi:10.4172/2329-6607.1000159

Page 3 of 5

six variables were not significantly different among the groups. These included troponin-I serum level, size of the infarcted region calculated by JImage software, and thickness of the normal area calculated by calipers ( $\mathrm{p}$ value $=0.17,0.70$ and 0.14 respectively).

We used a scoring system for comparing RWMA (from 0 to 6). As shown in Table 1, the scores of case group canines were 1,1 and 2 . The mean \pm SD RWMA score of the chitosan and control groups were $3.00 \pm 0.00$ and $2.75 \pm 0.50$, respectively. As shown in Table 2, post-MI RWMA scores were significantly lower in the GLP-1+chitosan group ( $\mathrm{p}$ value $=0.02$ ).
A four-scale scoring system was used to make angiogenesis a quantitative variable. Our case group scored 3 on average in both HandE and CD34 staining for angiogenesis, which is significantly higher than the scores of the chitosan and control groups ( $\mathrm{p}$ value= 0.02 for both $\mathrm{H}$ and $\mathrm{E}$ and CD34) (Table 2).

The thickness of infarcted parts, calculated by calliper, was significantly higher in canines of the case group compared with the others $(\mathrm{p}$ value $=0.023)$.

\begin{tabular}{|c|c|c|c|c|c|c|c|c|}
\hline & & $\begin{array}{l}\text { Troponin I (ng/ } \\
\text { ml) }\end{array}$ & CD34 & RWMA & Image $\mathbf{J}$ & $\begin{array}{l}\text { Normal thickness } \\
\text { (cm) }\end{array}$ & $\begin{array}{l}\text { Infarction thickness } \\
\text { (cm) }\end{array}$ & Angiogenesis ( $\mathrm{H}$ and $\mathrm{E}$ ) \\
\hline & & & & & & 1.4 & & \\
\hline \multirow[t]{4}{*}{ Control } & week 4 & 300 & 1 & 3 & 0.342 & & 0.6 & 1 \\
\hline & week 8 & 350 & 2 & 3 & 0.071 & 1.2 & 0.7 & 2 \\
\hline & week 12 & 200 & 1 & 2 & 0.148 & 1.4 & 0.6 & 1 \\
\hline & week 16 & 250 & 1 & 3 & 0.116 & 1 & 0.5 & 1 \\
\hline \multirow[t]{4}{*}{ Chitosan } & week 4 & 250 & 1 & 3 & 0.354 & 1.1 & 0.6 & 1 \\
\hline & week 8 & 200 & 1 & 3 & 0.059 & 1.5 & 0.8 & 1 \\
\hline & week 12 & 300 & 2 & 3 & 0.146 & 1.5 & 1 & 2 \\
\hline & week 16 & 370 & 2 & 3 & 0.084 & 1.3 & 0.8 & 2 \\
\hline \multirow[t]{4}{*}{ GLP-1+Chitosan } & week 4 & 400 & 3 & 1 & 0.073 & 1.3 & 1.1 & 3 \\
\hline & week 8 & 300 & 3 & 1 & 0.15 & 1.4 & 1.1 & 3 \\
\hline & week 12 & 700 & 3 & 2 & 0.587 & 1.4 & 1 & 3 \\
\hline & week 16 & - & - & _ & - & - & - & - \\
\hline
\end{tabular}

Table 1: Change in cardiac variables in four weeks periods.

\begin{tabular}{|c|c|c|c|c|}
\hline & & n & Mean SD & $p$ value \\
\hline \multirow[t]{4}{*}{ Troponin I } & control & 4 & $275.00 \pm 64.55$ & \multirow[b]{4}{*}{0.17} \\
\hline & chitosan & 4 & $280.00 \pm 72.57$ & \\
\hline & GLP-1+chitosan & 3 & $466.67 \pm 208.16$ & \\
\hline & Total & 11 & $329.09 \pm 138.95$ & \\
\hline \multirow[t]{4}{*}{ CD34 } & control & 4 & $1.25 \pm 5.00$ & \multirow[b]{4}{*}{0.02} \\
\hline & chitosan & 4 & $1.50 \pm 0.57$ & \\
\hline & GLP-1+chitosan & 3 & $3.00 \pm 0.00$ & \\
\hline & Total & 11 & $1.82 \pm 874$ & \\
\hline \multirow[t]{4}{*}{ RWMA } & control & 4 & $2.75 \pm 0.50$ & \multirow[b]{4}{*}{0.02} \\
\hline & chitosan & 4 & $3.00 \pm 0.00$ & \\
\hline & GLP-1+chitosan & 3 & $1.33 \pm 0.57$ & \\
\hline & Total & 11 & $2.45 \pm 0.82$ & \\
\hline \multirow[t]{5}{*}{ Image J } & control & 4 & $0.16 \pm 0.11$ & \multirow[b]{5}{*}{0.7} \\
\hline & chitosan & 4 & $0.16 \pm 0.13$ & \\
\hline & GLP-1+chitosan & 3 & $0.27 \pm 0.27$ & \\
\hline & Total & 11 & $0.19 \pm 0.16$ & \\
\hline & & & & \\
\hline \multirow[t]{4}{*}{ Normal thickness (cm) } & control & 4 & $1.00 \pm 0.00$ & \multirow[b]{4}{*}{0.14} \\
\hline & chitosan & 4 & $1.50 \pm 0.57$ & \\
\hline & GLP-1+chitosan & 3 & $1.00 \pm 0.00$ & \\
\hline & total & 11 & $1.18 \pm 0.40$ & \\
\hline \multirow[t]{4}{*}{ Infarction thickness (cm) } & control & 4 & $0.60 \pm 0.08$ & \multirow[b]{4}{*}{0.02} \\
\hline & chitosan & 4 & $0.80 \pm 0.16$ & \\
\hline & GLP-1+chitosan & 3 & $1.06 \pm 0.05$ & \\
\hline & Total & 11 & $0.80 \pm 0.21$ & \\
\hline \multirow[t]{4}{*}{ Angiogenesis ( $\mathrm{H}$ and $\mathrm{E}$ ) } & control & 4 & $1.25 \pm 0.5$ & \multirow[b]{4}{*}{0.02} \\
\hline & chitosan & 4 & $1.50 \pm 0.57$ & \\
\hline & GLP-1+chitosan & 3 & $3.00 \pm 0.00$ & \\
\hline & Total & 11 & $1.82 \pm 0.87$ & \\
\hline
\end{tabular}

Table 2: Comparing cardiac variables by different treatments.

GLP-1: Glucagon-Like Peptide 1; H and E: Hematoxylin and Eosin; RWMA: Regional Wall Motion Abnormality 
Citation: Zeraatian S, Salehiomran A, Aghdam RM, Tafti SHA, Ghiasi SR (2015) Cardiac Effects of Glucagon-Like Peptide 1 with Chitosan-Based Scaffold after Inducing Myocardial Infarction in Dogs. Cardiol Pharmacol 4: 159. doi:10.4172/2329-6607.1000159

Page 4 of 5

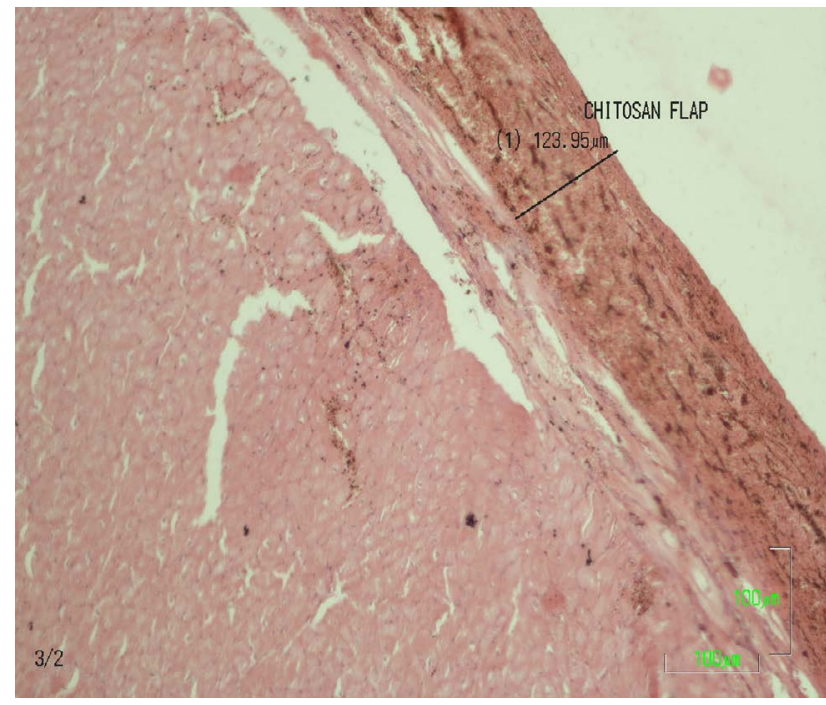

Figure 5: Hematoxylin and eosin ( $\mathrm{H}$ and $\mathrm{E})$ staining of cardiac tissue.

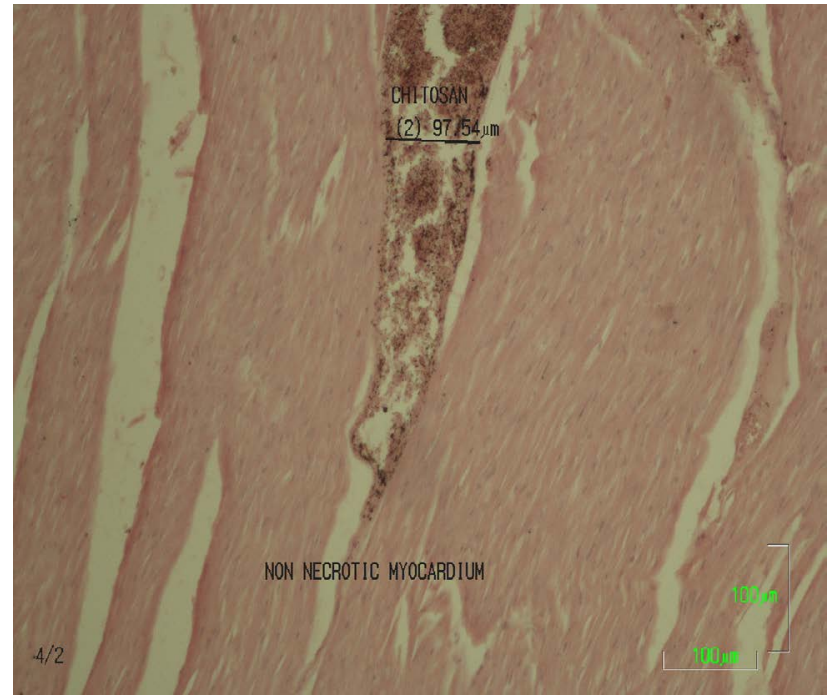

Figure 6: Chitosan penetration into myocardium

\section{Discussion}

Type 2 diabetes mellitus increases the risk of cardiovascular disease not only because of hyperglycemia, but also because of comorbidities like dyslipidemia, hypertension, and obesity $[9,10]$. Recently, incretinbased antidiabetes treatment has been recommended, as it reduces glycemia without the risk of hypoglycemia or weight gain seen with most antidiabetes agents $[11,12]$. Vasodilation and anti-inflammatory effects of native GLP-1 in the vascular endothelium and myocardium make GLP-1 one of the preferred treatments for type 2 diabetes mellitus [13-15]. DPPIV makes the half-life of native GLP-1 extremely short, because it inactivates GLP-1 even before it leaves the gut [16]. In addition to using GLP-1 analogues like exenatide, which are not subject to native GLP-1 rapid inactivation, scaffolds like chitosan can be used in conjunction with GLP-1. A chitosan scaffold prolongs the duration of GLP-1 release. In this animal-based study, we compared the cardiac effects after MI of GLP-1 plus chitosan with chitosan only and placebo treatment.
The cardioprotective effect of GLP-1 has been successfully demonstrated in recent studies. Sokos et al. demonstrated that adding a 5 -week infusion of GLP-1 $(2.5 \mathrm{pmol} / \mathrm{kg} / \mathrm{min})$ to standard therapy in patients with New York Heart Association class III/IV heart failure significantly improved left ventricular ejection fraction, maximum myocardial ventilation oxygen consumption, 6 minute walk distance, and Minnesota Living with Heart Failure Quality of Life score [17]. Nikolaidis and his colleagues revealed that $72 \mathrm{hr}$ infusion of GLP-1 in patients with left ventricular dysfunction leads to improvement in global and regional wall motion scores [18]. The amelioration of left ventricular function by GLP-1 infusion after percutaneous coronary intervention or stress-induced ischemia in patients with coronary artery disease has also been investigated $[19,20]$. In this study, we used a chitosan scaffold for GLP-1 instead of infusion, and the post-MI canine hearts treated with this new method had significant lower RWMA than those of chitosan-only and placebo-treated groups (Table 2).

Neovascularization through angiogenesis can re-establish the perfusion of ischemic heart regions after MI and result in improved prognosis. It can reduce the ischemic injury of myocardium specifically in unsuccessful revascularization [21-23]. An in-vitro study has shown that GLP-1 can promote angiogenesis through the PI3K/Akt, PKA, and Src pathways. This is a dose-dependent response, with the maximal effect detected at $500 \mathrm{nmol} / \mathrm{L}$ [24]. In this investigation, angiogenesis was examined using $\mathrm{H}$ and $\mathrm{E}$ and $\mathrm{CD} 34$ staining. As demonstrated in table 2, after MI, angiogenesis was significantly increased in the case group (treated with GLP-1+chitosan) compared with the other two groups, in both staining methods.

Although cardiac pseudoaneurysms are rare, it is very important to consider the risk of rupture. Surgical or percutaneous closure is used in most cases to reduce the risk of pseudoaneurysm expansion or rupture. Higher wall thickness reduces the risk of pseudoaneurysm by reducing wall stress, according to Laplace's law [wall stress $=($ pressure $/ 2) \times$ (radius/wall thickness)] [25]. As demonstrated in table 2, the thickness of the infarcted areas was significantly higher in our case group than in the other groups. This means that treatment with GLP-1 and chitosan after MI can decrease the risk of cardiac pseudoaneurysm.

As our limitation, common comorbidities like hypertension, dyslipidemia, and diabetes might influence the cardioprotective influences of GLP-1; this is not evaluated in this study.

\section{Conclusion}

This investigation revealed that there is a new way for consuming native GLP-1 other than using GLP-1 analogues like exenatide, GLP-1 infusion, or DPPIV inhibitors. This new method is putting GLP-1 on a chitosan scaffold to repel rapid intact GLP-1 inactivation. This novel compound (GLP-1+chitosan) has cardioprotective effects after MI. It significantly lowers RWMA and the risk of cardiac pseudoaneurysm and increases angiogenesis in post-MI canines.

\section{Acknowledgment}

The authors wish to thank Dr. M Sotuode for contributing in pathologic parts of this article, Dr. M Sabet for helping us for echocardiography, Dr. R Ghiassi for involving in veterinary surgeries and all crew of the Clinical Experiments Department of THC, Tehran University of Medical Sciences (TUMS), Tehran, Iran.

\section{Funding}

This work was supported by Tehran Heart Center (THC), Tehran University of Medical Sciences (TUMS), Tehran, Iran. 
Citation: Zeraatian S, Salehiomran A, Aghdam RM, Tafti SHA, Ghiasi SR (2015) Cardiac Effects of Glucagon-Like Peptide 1 with Chitosan-Based Scaffold after Inducing Myocardial Infarction in Dogs. Cardiol Pharmacol 4: 159. doi:10.4172/2329-6607.1000159

Page 5 of 5

\section{References}

1. Goke R, Fehmann HC, Linn T, Schmidt H, Krause M, et al. (1993) Exendin-4 is a high potency agonist and truncated exendin-(9-39)-amide an antagonis at the glucagon-like peptide 1-(7-36)-amide receptor of insulin-secreting betacells. J Biol Chem 268: 19650-19655.

2. Wei Y, Mojsov S (1995) Tissue-specific expression of the human receptor for glucagon-like peptide-l: brain, heart and pancreatic forms have the same deduced amino acid sequences. FEBS Lett 358: 219-224.

3. Vila Petroff MG, Egan JM, Wang X, Sollott SJ (2001) Glucagon-like peptide-1 increases CAMP but fails to augment contraction in adult rat cardiac myocytes. Circ Res 89: 445-452.

4. Zhao TC (2013) Glucagon-like peptide-1 (GLP-1) and protective effects in cardiovascular disease: A new therapeutic approach for myocardial protection. Cardiovasc Diabetol 12: 90

5. Bose AK, Mocanu MM, Carr RD, Brand CL, Yellon DM (2005) Glucagon-like peptide 1 can directly protect the heart against ischemia/reperfusion injury. Diabetes 54: 146-151.

6. Deacon CF, Hughes TE, Holst JJ (1998) Dipeptidyl peptidase IV inhibition potentiates the insulinotropic effect of glucagon-like peptide 1 in the anesthetized pig. Diabetes 47: 764-769.

7. VandeVord PJ, Matthew HW, DeSilva SP, Mayton L, Wu B, et al. (2002) Evaluation of the biocompatibility of a chitosan scaffold in mice. J Biomed Mater Res 59: 585-590.

8. Zhu C, Fan D, Duan Z, Xue W, Shang L, et al. (2009) Initial investigation of novel human-like collagen/chitosan scaffold for vascular tissue engineering. Journal of biomedical materials research Part A 89: 829-840.

9. Buse JB, Ginsberg HN, Bakris GL, Clark NG, Costa F, et al. (2007) Primary prevention of cardiovascular diseases in people with diabetes mellitus: A scientific statement from the American Heart Association and the American Diabetes Association. Circulation 115: 114-126.

10. Eeg-Olofsson K, Cederholm J, Nilsson PM, Zethelius B, Nunez L, et al. (2009) Risk of cardiovascular disease and mortality in overweight and obese patients with type 2 diabetes: an observational study in 13,087 patients. Diabetologia 52: $65-73$.

11. Rodbard HW, Jellinger PS, Davidson JA, Einhorn D, Garber AJ, et al. (2009) Statement by an American Association of Clinical Endocrinologists/American College of Endocrinology consensus panel on type 2 diabetes mellitus: An algorithm for glycemic control. Endocrine practice: Official journal of the American College of Endocrinology and the American Association of Clinical Endocrinologists 15:540-559.

12. Nathan DM, Buse JB, Davidson MB, Ferrannini E, Holman RR, et al. (2009) Medical management of hyperglycemia in type 2 diabetes: A consensus algorithm for the initiation and adjustment of therapy: A consensus statement of the American Diabetes Association and the European Association for the Study of Diabetes. Diabetes care 32:193-203.

13. Ban K, Noyan-Ashraf MH, Hoefer J, Bolz SS, Drucker DJ, et al. (2008) Cardioprotective and vasodilatory actions of glucagon-like peptide 1 recepto are mediated through both glucagon-like peptide 1 receptor-dependent and -independent pathways. Circulation 117: 2340-2350

14. Noyan-Ashraf MH, Momen MA, Ban K, Sadi AM, Zhou YQ, et al. (2009) GLP-1R agonist liraglutide activates cytoprotective pathways and improves outcomes after experimental myocardial infarction in mice. Diabetes 58:975-983.

15. Ishibashi Y, Matsui T, Takeuchi M, Yamagishi S (2010) Glucagon-like peptide-1 (GLP-1) inhibits advanced glycation end product (AGE)-induced up-regulation of VCAM-1 mRNA levels in endothelial cells by suppressing AGE recepto (RAGE) expression. Biochemical and biophysical research communications 391: 1405-1408.

16. Holst JJ (2007) The physiology of glucagon-like peptide 1. Physiol Rev 87 1409-1439.

17. Sokos GG, Nikolaidis LA, Mankad S, Elahi D, Shannon RP (2006) Glucagonlike peptide-1 infusion improves left ventricular ejection fraction and functional status in patients with chronic heart failure. J Card Fail 12: 694-699.

18. Nikolaidis LA, Mankad S, Sokos GG, Miske G, Shah A, et al. (2004) Effects of glucagon-like peptide-1 in patients with acute myocardial infarction and left ventricular dysfunction after successful reperfusion. Circulation 109: 962-965.

19. Read PA, Hoole SP, White PA, Khan FZ, O'Sullivan M, et al. (2011) A pilot study to assess whether glucagon-like peptide-1 protects the heart from ischemic dysfunction and attenuates stunning after coronary balloon occlusion in humans. Circulation Cardiovascular interventions 4: 266-272.

20. Read PA, Khan FZ, Dutka DP (2012) Cardioprotection against ischaemia induced by dobutamine stress using glucagon-like peptide- 1 in patients with coronary artery disease. Heart (British Cardiac Society) 98: 408-413.

21. Billinger M, Kloos P, Eberli FR, Windecker S, Meier B, et al. (2002) Physiologically assessed coronary collateral flow and adverse cardiac ischemic events: a follow-up study in 403 patients with coronary artery disease. Journal of the American College of Cardiology 40: 1545-1550.

22. Jaffer FA, Sosnovik DE, Nahrendorf M, Weissleder R (2006) Molecular imaging of myocardial infarction. J Mol Cell Cardiol 41: 921-933.

23. Ahn A, Frishman WH, Gutwein A, Passeri J, Nelson M (2008) Therapeutic angiogenesis: A new treatment approach for ischemic heart disease--Part II. Cardiology in review 16: 219-229.

24. Aronis KN, Chamberland JP, Mantzoros CS (2013) GLP-1 promote angiogenesis in human endothelial cells in a dose-dependent manner, through the Akt, Src and PKC pathways. Metabolism 62: 1279-1286.

25. Hulten EA, Blankstein R (2012) Pseudoaneurysms of the heart. Circulation 125: $1920-1925$ 